\title{
6
}

\section{NAS MÃOS DO ARTISTA, A CRIAÇÃO: A LITERATURA E O CINEMA NO ENSINO DO “DIFERENTE” 1}

\author{
IN THE HANDS OF THE ARTIST, CREATION: LITERATURE \\ AND CINEMA IN THE TEACHING OF THE “DIFFERENT”
}

\author{
Weslei Chaleghi de Melo² \\ Universidade Estadual de Londrina \\ Wilder Kleber Fernandes de Santana ${ }^{3}$ \\ Universidade Federal da Paraíba \\ Isabel Cristina Cordeiro ${ }^{4}$ \\ Universidade Estadual de Londrina
}

\begin{abstract}
Resumo: Neste estudo buscamos focalizar as múltiplas formas de expressão artística que compenetram a linguagem, relacionando a literatura e o cinema. Para tanto, desenvolvemos um diálogo que envolveu duas obras, uma literária (Elmer, o elefante xadrez) e outra cinematográfica (Dumbo). Procuramos apresentar brevemente a função social da arte e como ela pode ser inserida dentro de diversas discussões em sala de aula com enfoque na diversidade, trabalhando com conceitos de arte e literatura escola. Por meio da análise foi possível constatar que ambas as obras apresentam temas pedagógicos e literariamente relevantes para a reflexão aqui proposta, ou seja, diversidade e educação por meio da literatura e do cinema se constituem como recursos valiosos e que despertam nos alunos e nos professores sentimentos de alteridade.
\end{abstract}

Palavras-Chave: Crítica cinematográfica; Crítica literária; Diversidade.

1 O termo "diferente" será utilizado entre aspas no decorrer do trabalho para fazer menção ao conceito já estigmatizado socialmente, querendo significar algo/alguém que foge dos padrões impostos pela sociedade, em analogia aos termos "normal" e "normalidade" usados por Venâncio (2009).

2 Endereço eletrônico: weslei@alunos.utfpr.edu.br.

3 Endereço eletrônico: wildersantana92@gmail.com.

4 Endereço eletrônico: isabel-cordeiro@uol.com.br. 
Abstract: In this study we seek to focus on the multiple forms of artistic expression that permeate language, relating literature and cinema. Therefore, we developed a dialogue that involved two works, one literary (Elmer, the chess elephant) and the other cinematographic (Dumbo). We seek to briefly present the social function of art and how it can be inserted into diverse classroom discussions with a focus on diversity, working with concepts of art and school literature. Through the analysis, it was possible to verify that both works have pedagogical and literarily relevant themes for the reflection proposed here, that is, diversity and education through literature and cinema are valuable resources that awaken feelings in students and teachers. of alterity.

Keywords: Film criticism; Literary criticism; Diversity.

\section{INTRODUÇÃO}

Neste trabalho, buscamos focalizar a literatura e o cinema como formas de expressão artística que compenetram a linguagem, o que já fora evidenciado por Melo, Silveira \& Santana em artigo intitulado Literatura e cinema em interação discursiva: a valor(iz)ação do eu na educação especial (2020). O reconhecimento da potencialidade dessas reflexões sobre temas que envolvem o "diferente" pode contribuir positivamente para o amadurecimento crítico de sujeitos em seus vários aspectos.

No percurso de delimitação do corpus, utilizamos como objetos de estudo duas obras que trazem de forma didática, a diversidade como manifestação da alteridade, além de explicitarem os motivos que temos, enquanto sociedade, para aceitar o outro e a nós mesmo enquanto cidadãos. Foram selecionadas, na literatura infanto-juvenil, o livro Elmer, o elefante xadrez (MCKEE, 2009), e na produção cinematográfica o desenho Dumbo (FERGUSON, 1941), que pode ser considerado um clássico de Walt Disney. Usamos ambas as obras de linguagens diferentes, fílmica e literária, para gerar uma discussão sobre a diversidade em tom de problematização em sala. Além disso, trouxemos em pauta a discussão em relação à arte, sua função social e seu uso na escola, com uma reflexão do papel da literatura na escola e ela como foco para propor um olhar diferenciado sobre a diversidade. 
Ancorados em Silveira e Santana (2019), entendemos que a participatividade do sujeito no agir alteritário "inaugura, a cada instante, sua essência e potencialidade ativa para o dizer-Ato, visto que o sujeito ocupa na sociedade múltiplas identidades, pois está sempre em contato com diferentes interlocutores" (SILVEIRA; SANTANA, 2019, p. 93).

Por meio de uma postura ético-responsiva (BAKHTIN, 2006 [1979]), na medida em que nos identificamos como pesquisadores, acreditamos ser pertinente deixar marcadas algumas referências adotadas que robustecem as entrelinhas desse estudo. Alguns dessas pesquisas se desdobram nos dizeres de Bosi (1974), Candido (1995) e Cosson (2006), além de manuscritos mais recentes, a exemplo do trabalho de Duarte (2009), que trata da relação cinematográfica como instrumento pedagógico nos processos de ensino e aprendizagem, e de Gualda (2010), que discute as relações entre literatura e cinema em níveis teóricos, considerando seus elos e diferenças.

O nosso objetivo, nesse sentido, consiste em analisar de que maneira obras cinematográficas ou literárias (voltadas ao público infantil), podem contribuir para compreensão de conceitos relativos à diversidade, à aceitação do próximo e, principalmente, ao desenvolvimento do sentimento de alteridade. Esta investigação justifica-se por discutir um tema que atualmente possui grande relevância e preocupa, desde a virada para o século XXI, acadêmicos de diferentes áreas, tais como a narratologia (SCHOWLZ, 1998), a cognição em literatura (KEUNEN, 2000), e fenômenos plástico-picturais (NÓBREGA, 2019). Realizar tal discussão, com o uso de recursos que possam vir a ser praticáveis dentro das propostas de professores, portanto, tornou-se foco de nossa pesquisa.

Em aspectos estruturais, além da Introdução, Considerações finais e Referências, o estudo está dividido em três seções: 1) Da função social da arte e a educação, 2) Literatura, alteridade e o potencial educativo e 3) Elmer e Dumbo: elefantes à procura de pertencimento, constituindo, esse último, o ato analítico. 
Desde os primeiros artefatos de arte encontrados (GOMBRICH, TORROELLA, 1997), nota-se um propósito: a sua apreciação e das demais obras produzidas pelo homem, abarcando a noção da técnica, o valor moral e social (de coesão) por eles expressos, que sempre articulavam/articulam algum interesse voltado a uma finalidade em sua produção. Duarte (1998) nos ajuda a compreender que se torna mister dirimir dúvidas, de forma que "arte-educação não significa o treino para alguém se tornar um artista, não significa a aprendizagem de uma técnica, num dado ramo das artes" (DUARTE, 1998, p. 33). Ao contrário, sua significação se aproxima de conceitos de base subjetiva com a potencialidade dos sujeitos que constituem o processo educacional.

No momento em que a arte possuía apenas a função de focalizar aspectos do belo, surgem os cursos de "Belas-Artes" (GOMBRICH, TORROELLA, 1997), nos quais as produções vinculam-se ao valor estético. Assim, à arte estiveram vinculadas duas propriedades distintas da percepção humana, sendo elas o entendimento e a imaginação, ambas se concretizando na obra do artista. Nessas instâncias interpretativas, "Ela [a arte] está sempre a inventar a sua própria sintaxe e o artista está sempre a transgredir criativamente tais regras. Para que a obra tome lugar, o artista comunica um sentido" (TAVARES, 2003, p. 45). Ainda de acordo com Tavares (2003), há três determinações no que tange à produção artística humana: o aspecto físico da realidade, que por sua vez já está determinado; o aspecto semântico (dessa vez inserido na realidade social), que é convencionado pela comunidade; e, por fim, o aspecto subjetivo, que se insere na singularidade e na individualidade do artista. Desse modo, conclui Tavares (2003): 
Portanto, na arte, diferentemente da ciência, o sentido não pode ser rigorosamente codificado; é a própria obra que fala e se abre ao receptor não como conhecimento, mas como ambivalência e ambiguidade. [...] se a arte é conhecimento, ela o é no modo próprio e inconfundível que lhe deriva do seu ser arte. E sendo experiência sensível, ela inventa ao mesmo tempo em que constrói o seu objeto, que só é dado a conhecer pela sua forma particular de elaboração e pelo seu modo de existência sensível. E só assim ele se prolonga à contemplação. (TAVARES, 2003, p. 34)

Nesse sentido, a arte, enquanto signo ideológico, não apresenta uma objetividade pura (VOLÓCHINOV, 2917 [1929]), não há modos de “quantificála", em nenhum de seus aspectos, pois a subjetividade presente no artista também se encontra presente no observador/apreciador. Nem toda mensagem idealizada pelo artista atinge o receptor da mesma forma, visto que a interpretação, baseada no repertório de quem a contempla, influencia sua decodificação.

A arte, além dos aspectos já citados, desempenha um papel muito importante na escola e na vida da criança, pois possui, dentre outras finalidades, a função de expressar os sentimentos. Sendo assim, tal representação se faz a partir de símbolos, que podem também ser chamados de "ideias de sentimento", ou seja, a ideia que se tem dos sentimentos materializada em uma obra (TAVARES, 2003, p. 30).

Outro aspecto da arte que tem um importante papel na formação humana é a do desenvolvimento da criatividade (BAHIA, 2002; DOMINGUES, 2003). Competências e ou habilidades previstas em documentos legais brasileiros não propõem a utilização da arte apenas durante produções artísticas, como muitos pensam, mas pode ser a base para a resolução de problemas e conflitos, tendendo a facilitar a compreensão de produções não artísticas que, ao desvendar o mundo para o indivíduo, mostra-lhe aspectos da realidade, inclusive em fatores emocionais (MACHADO; STOLTZ, 2017). 


\section{LITERATURA, ALTERIDADE E O POTENCIAL EDUCATIVO}

A literatura infanto juvenil, de acordo com Venâncio (2009), pode trazer o sentimento de alteridade nos ouvintes/leitores, ou seja, por meio da literatura, eles podem se colocar no lugar do outro, do diferente e do igual, além de revisarem práticas sociais, preconceitos e posturas perante a sociedade e a individualidade. Trata-se de um tema que vem sendo evidenciado em diversos intercaminhos de periódicos em âmbito vernáculo (NUNES, 2013; DALCASTAGNÈ, 2019; MELO; SILVEIRA; SANTANA, 2020).

Somos de partilha dos pontos de vista defendidos pelos pesquisadores supracitados de que a literatura, caso não seja trabalhada tendo em vista especificidades teóricas e subjetivas, pode provocar um certo desconforto no leitor, de forma que repense certas questões o que, sem ela, provavelmente não seria possível.

O leitor busca, no seu contato com o objeto livro, se conectar a outras experiências de vida, buscando entender o que é ser o outro, morar em terras longínquas, falar uma língua estranha, ter outro sexo, um modo diferente de enxergar o mundo. Assim, a literatura infanto-juvenil, como outros gêneros literários, se constitui como um importante artefato cultural difusor de mensagens, reforçando atitudes, legitimando discursos, fortalecendo estigmas, mantendo ideologias. (VENÂNCIO, 2009, p. 53)

Vale lembrar que nem toda obra literária é capaz de trazer tais reflexões. Cabe, muitas vezes, ao professor selecioná-las de forma com que a leitura tenha finalidades que ultrapassem a apreciação estética e desconstrua estigmas sociais. Assim como qualquer produção artística potencialmente desenvolve a construção da identidade e a distinção entre o "eu" e o "outro", podemos perceber tal relação também bastante presente na literatura infantojuvenil.

Para fundamentar a noção de que a exclusão de alguns grupos sociais acontece por conta de relações estritamente sociais e jamais a partir de dados 
objetivos, na realidade, Venâncio (2009) reporta-se ao interacionismo simbólico ${ }^{5}$. Nesta abordagem, há a ideia de que a inferiorização ou valorização de um determinado grupo ocorre a partir de uma realidade socialmente construída e interiorizada pelos indivíduos, inclusive com as próprias vítimas, como veremos adiante com o elefante Elmer, criação de Mckee (2009), que se sente inferiorizado por ser diferente.

As experiências individuais e sociais mesclam-se a fim de formar a completude do sujeito. Portanto, é na educação da primeira infância, de acordo com Venâncio (2009), que se deve incutir na criança a noção de diversidade. Assim, o indivíduo cresce pautando-se na atitude do outro (professores e demais alunos), havendo o apreço pela convivência com o "diferente". E para fundamentar tais representações, o uso de materiais artísticos pode ser imprescindível. Dessa forma, "[...] a atitude do Outro estabeleceria "parâmetros" para direcionar ações, estabelecendo critérios de valoração e ajuizamento que norteariam o modo de cada um se comportar no contexto social" (VENÂNCIO, 2009 , p. 28-9) ${ }^{6}$.

Com isso, os alunos e a sociedade assumiriam uma linguagem comum, nela inseridas as diferenças, sendo que estas, a priori e a posteriori, não revelariam graus de superioridade e/ou inferioridade, uma vez que fazem parte da riqueza

\footnotetext{
5 Ser-nos-ia impossível, para os propósitos desse trabalho, realizar um tratado sobre essa categoria, que é tão cara aos estudos comportamentais e especificamente ao campo da Psicologia Social. Trata-se de uma perspectiva de estudos "que possibilita a compreensão do modo como os indivíduos interpretam os objetos e as outras pessoas com as quais interagem e como tal processo de interpretação conduz o comportamento individual em situações específicas" (CARVALHO; BORGES; RÊGO, 2010, p. 148). No que diz respeito às origens dessa perspectiva conhecida como interacionismo simbólico, remonta-se a representantes da Escola de Chicago, "como Charles Cooley, John Dewey, William Thomas e, sobretudo, George Mead, considerado o principal precursor e inspirador do movimento interacionista" (CARVALHO; BORGES; RÊGO, 2010, p. 148).

6 As relações entre pares seriam, nesse prisma, norteadas por critérios construídos e significados socialmente, com a negação da diferença e da diversidade gerando conflitos que desgastam relacionamentos e promovem a estigmatização e o consequente fortalecimento de atitudes discriminatórias baseadas em preconceitos (VENÂNCIO, 2009, p. 28-9).
} 
da cultura, da etnia e de diversos aspectos que configuram a humanidade. Entenderiam, além disso, que os estigmas e a classificação de indivíduos, na maioria das vezes, pormenorizam tudo que é tido como diferente. Por exemplo, um sujeito não pode ser classificado por conta de fenótipos, orientações sexuais, religiosas, dentre outras. Mais à frente, discutiremos a obra cinematográfica Dumbo que mostra claramente um elefante que portava um fenótipo (orelhas grandes) e, por esse motivo, era excluído e colocado à margem, sendo que tal característica não alterava em nada sua essência.

\title{
3 ELMER E DUMBO: ELEFANTES À PROCURA DE PERTENCIMENTO
}

Para a escolha de tais obras, utilizamos critérios que tratassem de temas voltados à diversidade e que, em momento algum, como acontece em alguns livros de literatura infantojuvenil dessa temática, apresentassem estereótipos negativos. Logo, buscamos na literatura e no cinema retratações que não tivessem somente boas intenções, e sim que conseguissem desconstruir estigmas sociais.

\begin{abstract}
Pensando na literatura como fonte de conhecimento, e no livro como interface entre o leitor e as ideias ali contidas, a literatura infanto-juvenil pode ser um canal de formação e informação das crianças e jovens, entretanto, se essas histórias representarem a deficiência com elementos explícitos e implícitos geradoras, propiciadoras e solidificadoras de estereótipos e preconceito com relação à deficiência, não estarão condizentes com o momento em que se vislumbra a inclusão escolar e social da pessoa com deficiência. (NORONHA, 2006, p. 15)
\end{abstract}

Na capa do livro Elmer, o elefante xadrez", podemos observar um desenho: um elefante xadrez, com um fundo também xadrez e colorido. A obra, em suas

\footnotetext{
7 A obra foi publicada inicialmente com o nome Elmer. O nome de tradução para o Português brasileiro é Elmer, o elefante xadrez. Autor: David L. Mckee. Trad. Mônica Stahel. Ano da $1^{\text {a }}$ edição: 2009, na Inglaterra, com 36 páginas, dentre as quais várias ilustradas.
} 
ilustrações, traz elementos meramente ficcionais voltados ao público infantil como as cores vivas, uma narrativa que utiliza palavras do cotidiano das crianças e, além disso, carrega uma forte expressão simbólica. Dessa forma, ao iniciar a leitura do livro de Mckee (2009), podemos deduzir que a reação de crianças perante a obra seria a de estranhamento e de levantamento de hipóteses a respeito do seu conteúdo (MELO, 2020).

No início da narrativa, Mckee (2009) apresenta uma manada de elefantes na qual todos eram cinzas, o que de certa forma causava um grande desconforto em Elmer. O diferencial dele, um elefante xadrez, não era tão somente o fato de possuir um aspecto distinto dos demais, mas sim "ser divertido", da forma que nenhum outro elefante era. Quando o elefantinho não estava com o grupo, só havia silêncio e nenhuma gargalhada. Ele tenta, por meio de vários artifícios, tornar-se cinza como os outros elefantes, porém suas tentativas são fracassadas e, por fim, aceita-se como um elefante diferente e com qualidades também diferentes dos demais (MELO, 2020).

Quando Elmer reencontrou os outros elefantes, estavam todos parados, muito quietos. Nenhum deles reparou em Elmer enquanto ele ia andando para o meio da manada. [...] com as risadas a nuvem escura rebentou, e quando a chuva caiu em Elmer seu xadrez foi aparecendo de novo. Os elefantes continuavam a rir, enquanto a água da chuva fazia Elmer voltar ao normal. (MCKEE, 2009, p. 7)

A proposta de Mckee (2009) é mostrar como às vezes o próprio sujeito, que é considerado "diferente", acaba ficando à margem no grupo. Elmer era querido entre os demais elefantes da manada, mas por ser "diferente" via-se como inferior. Trazer essa noção para o aluno, de que a diferença não traduz conceitos hierárquicos, pode ser uma das efetivas ferramentas para o processo de aceitação e participação na diversidade.

Sendo assim, a aceitação, além dos aspectos sociais, possui aspectos individuais. A história de Mckee (2009) mostra claramente que o elefante era 
aceito pela manada, entretanto, não era aceito por si mesmo. Duas reflexões/intervenções podem ser feitas pelo professor: a primeira, de que é importante aceitar-se; e a segunda, de que é importante, assim como na manada de Elmer, que o grupo facilite a inserção daquele membro que se sente à margem do coletivo.

Elmer, na perspectiva de Venâncio (2009), poderia ser caracterizado como aquele que se insere dentro do processo de estigmatização. Há, em algumas sociedades (se não todas), duas categorias de indivíduos: os que podem ser estigmatizados, por conta de alguma característica que foge do padrão; e aqueles que não podem ser estigmatizados, por fazerem parte dessa instituição chamada "normalidade". A estigmatização, além de ser em grande parte excludente, fundamenta-se a partir da classificação e da categorização de indivíduos e, após isso, criam-se conceitos sobre indivíduos e grupos que estão "à margem" social.

De acordo com tais estudos sobre processos de estigmatização, há, socialmente, presença de pessoas consideradas estigmatizadas ou estigmatizáveis e, em contraponto, aqueles que não se afastam negativamente das expectativas particulares, indivíduos considerados como "normais". Explicita-se, nesse movimento de classificação e posterior categorização, o perigo que a diferença pode representar, racionalizando a animosidade baseada em outras diferenças como, por exemplo, a de classe social. Criam-se, dessa maneira, representações sobre a diferença sem que se reflita sobre seu significado social. (VENÂNCIO, 2009, p. 31)

No livro de Mckee (2009), percebemos que as representações sociais refletem no indivíduo de forma positiva ou negativa. No caso de Elmer, ocorreu negativamente, pois percebia-se que ele não se "encaixava" dentro do padrão socialmente construído pelos outros elefantes, que eram cinzas e nada engraçados. 
O filme $D u m b o^{8}$, por sua vez, é o menor longa metragem criado pelos estúdios Disney, com apenas 64 minutos. Além disso, foi produzido durante a Segunda Guerra Mundial, com um orçamento reduzido, e era a obra fílmica predileta de Walt Disney. Logo no início do filme, percebemos a máxima de Rousseau (1978, p.35) de que "todos os homens nascem livres e iguais". Também notamos cegonhas carregando os bebês e todas as mães os recebem da mesma forma, em pé de igualdade. Quando Dumbo chega ao aconchego materno, as companheiras de vagão zombam das condições dele, e em um dado momento o nomeiam, pejorativamente, de "Dumbo", quando seu nome, na verdade, era para ser "Jumbo", nome dado por sua mãe.

Posteriormente, um menino que foi visitar os elefantes também zomba das orelhas do pequeno elefante. Vale destacar que as orelhas desse garoto também eram demasiadamente grandes. Sendo assim, ele também poderia ser uma vítima social, entretanto não se percebia como tal. Ou talvez descarregasse no "outro", o que estava inconsciente no seu "eu".

Tal atitude, se não questionada e problematizada pelos professores e por pais pode tornar-se comum, transformando-se em bullying, na medida em que este conceito representa a ausência da alteridade, e se materializa em atos violentos, intencionais e repetidos contra alguém indefeso, que se torna a vítima.

A sociedade infantil, nessa fase, é fechada aos adultos e por vezes tem matrizes de crueldade. As peculiaridades físicas ou idiossincrasias das crianças constituem objeto de 'troca'. A crítica é pessoal e direta. Além da crítica severa, surge, também, a capacidade de julgamento, estabelece-se a noção de 'justiça' que acaba por eliminar o traidor, ou aquele que não obedece ao código ético imposto pelo grupo. (ENDERLE, 1985, p. 70)

\footnotetext{
8 O nome da obra no idioma original é Dumbo, e também foi traduzido para o Português brasileiro é com mesma titulação. Autor: Bem Sharpsteen, produtor da Disney Studios, em 1941, nos EUA. A duração do longa metragem é de 1 hora e 4 minutos.
} 
Há alguns diálogos, entre os elefantes do grupo, que deixam claro a separação entre os elefantes "normais" e os "diferentes" que, muitas vezes, não são "considerados" elefantes pelo grupo, por conta das diferenças. Tais práticas, de acordo com Hobsbawm (2007), são visíveis em boa parte do mundo enquanto se produzia a animação em 1940 e 1941, quando alguns grupos como judeus, negros, homossexuais não eram considerados, por muita gente, como humanos.

Percebemos tais diálogos em:

[Em uma das conversas entre as elefantas que dividiam o vagão com a mãe de Dumbo]

- Lembrem-se que nós, elefantes, sempre tivemos dignidade.

- A desgraça dele é a nossa humilhação.

- É verdade.

- Realmente é. Francamente, eu não comeria do mesmo fardo de feno que ele.

- Certo.

- Nem eu.

- Nem eu. Também acho isso. [...]

- Lá vem ele agora. Finjam que não o vêem.

- De agora em diante, ele não é mais... Um elefante. (FERGUSON, 1941, 00:21:52 - 00:22:13 min)

Assim como o elefante Elmer, Dumbo usa seus "defeitos" para fazer algo fantástico. No caso, voar com suas orelhas e, por se tornar notícia nacional, a causa dos elefantes presos ganha apoio de defensores, conseguindo libertar sua mãe. Mas até chegar a isso, Dumbo sofre inúmeras humilhações, trabalha como palhaço e é obrigado a saltar de alturas cada vez maiores por conta do tamanho de suas orelhas. Chegam a dizer que seres como ele não possuem sentimentos.

O discurso proferido pelo rato, que se tornou amigo de Dumbo em parte do enredo, é bastante interessante, pois ele acaba com a zombaria dos pássaros (possivelmente $\operatorname{corvos}^{9}$ ) e faz o espectador (crianças e adultos) repensar alguns conceitos. No discurso professado pelo rato, é dito:

9 Cabe aqui problematizar a questão dos pássaros: aqueles que olham de cima (nos dois sentidos- com desprezo), que julgam, que semeiam a discórdia, tais como corvos e abutres. 
[O Reverendo Roedor tem a palavra.]

- Deveriam estar envergonhados. Caras adultos, como vocês... Implicando com um órfão como ele. Imaginem terem sido afastados das mães quando bebê... Ninguém para colocá-los na cama... Nenhuma tromba carinhosa para aconchegá-los. Como se sentiriam se tivessem sido abandonados... Em um mundo cruel, insensível? E por quê? Eu pergunto, por quê? Só porque têm orelhas grandes, eles o chamam de monstro. É o alvo de risos do circo. E quando a mãe tentou protegê-lo... Ela foi colocada no xadrez. E, além disso, fizeram dele um palhaço! Socialmente, ele está acabado. Mas de que adianta falar com pássaros sem coração? Vão se divertindo. Riam dele. Agora que ele está por baixo, pisem. Vamos. (FERGUSON, 1941, 00:56:43 - 00:57:47 min)

Logo após tal "lição de moral”, os pássaros sentem-se envergonhados e tentam remediar a situação, oferecendo a "pena mágica" e incentivando Dumbo a voar. Ressalta-se que tal acontecimento induz o leitor a perceber-se também no papel de agressor. Logo, a chacota dos pássaros parecia inocente, e até motivo de arrancar risadas do telespectador, entretanto, depois do discurso do rato, qualquer um se sentiria envergonhado. Aqui reside uma diferença entre Dumbo e Elmer: o primeiro precisa de algo para provar à sociedade seu valor; Elmer tem o reconhecimento dos demais, não passa pelo o que Dumbo passou, mas no fim ambos terminam felizes e aceitos pelos demais ${ }^{10}$.

Tanto Dumbo quanto Elmer conseguem destacar-se a partir de suas diferenças. As obras, em seus efeitos, demostram que as diferenças podem ser um aspecto positivo, seja coletivamente e/ou individualmente. Ensinam-nos a nos percebermos felizes com nossas diferenças, e também nos fazem aceitar (com consciência, respeito e empatia) as diferenças do "outro" e tê-las como algo positivo e enriquecedor.

Diversas obras de ficção na literatura e no cinema usam o pássaro como representação, a exemplo das personagens criadas por Poe e Hitchcock.

10 Tais problematizações são encontradas em outras animações recentes como Rio (2011), Os Semfloresta (2006) e O Espanta Tubarões (2004). 
Sobre tal aspecto, Gadotti (1992) aponta a relevância de reconhecer o diferente, dentro da escola, e como tal reconhecimento poderá ser valioso no âmbito social:

[...] a diversidade cultural é a riqueza da humanidade. Para cumprir sua tarefa humanista, a escola precisa mostrar aos alunos que existem outras culturas além da sua. Por isso, a escola tem que ser local, como ponto de partida, mas tem que ser internacional e intercultural, como ponto de chegada. [...] Escola autônoma significa escola curiosa, ousada, buscando dialogar com todas as culturas e concepções de mundo. Pluralismo não significa ecletismo, um conjunto amorfo de retalhos culturais. Significa sobretudo diálogo com todas as culturas, a partir de uma cultura que se abre às demais. (GADOTTI, 1992, p. 23)

Neste aspecto, ensinar diversidade é ir além da cultura na qual o estudante está inserido, quebrando paradigmas e mostrando que todas as culturas possuem o mesmo valor. $\mathrm{O}$ "diferente", muitas vezes, é aquele que possui hábitos, crenças e costumes que não se assemelham ao seu habitual. Os alunos devem perceber que tais aspectos não são melhores nem piores em si. Além disso, a escola deve, como salienta Gadotti (1992), apresentar o pluralismo. Portanto, as diferentes culturas devem estar presentes no diálogo pedagógico e nos conteúdos escolares.

Ambas as obras fazem com o que seus leitores repensem a diversidade e mostram características que podem ser consideradas negativas e potenciais estigmas. Por outro lado, podem ser úteis ao grupo, como foi o caso das orelhas de Dumbo, em que, por causa delas, sua mãe foi liberta e Dumbo conseguiu sentir-se incluído na sociedade e no grupo em que vivia.

Além disso, as duas obras, por serem demasiadamente didáticas e de fácil compreensão, podem vir a se tornar recursos valiosos para o ensino da diversidade, podendo ser exploradas enquanto recursos artísticos, gerando discussões que envolvam a arte, principalmente, no que tange às linguagens do cinema e da literatura. 


\section{CONSIDERAÇÕES FINAIS}

O ensino da diversidade, em sala de aula, usando conceitos voltados para o público infantil, como as animações em longa metragem e a literatura infantojuvenil, podem ser valiosos para o trabalho com conceitos relativos ao diferente, ao desenvolvimento do sentimento de alteridade e até para que percebam características como fenótipos. Tais orientações podem ser formas relevantes de lutar contra o preconceito tanto no âmbito social quanto no individual.

Com o presente trabalho pretendemos focalizar a literatura e o cinema como formas de expressão artística que compenetram a linguagem. Acreditamos ter cumprido o objetivo ao qual nos propomos, que foi analisar de que maneira obras cinematográficas ou literárias (voltadas ao público infantil) podem contribuir para compreensão de conceitos relativos à diversidade, à aceitação do próximo e, principalmente, ao desenvolvimento do sentimento de alteridade.

As obras Elmer, o elefante xadrez e Dumbo podem ser utilizadas em sala de aula com diferentes faixas etárias. Ao trabalhar o tema diversidade com crianças e/ou adolescentes, com as duas obras, o foco será a aceitação do "diferente", da exclusão social e divisão econômica, dentre outras esferas.

\section{REFERENNCIAS}

BAHIA, Sara. Da educação à arte e à criatividade. 2002.

BAKHTIN, Mikhail. Estética da Criação Verbal. 4ª edição. Trad. Paulo Bezerra. Martins Fontes, 2006 [1979].

BOSI, Alfredo. Imagem, Discurso. Revista Discurso, v. 5, n. 5, p. 65-86, 1974.

CANDIDO, Antonio. O direito à literatura. São Paulo: Duas Cidades, 1995.

CARVALHO, Virgínia Donizete de; BORGES, Livia de Oliveira; RÊGO, Denise Pereira do. Interacionismo simbólico: origens, pressupostos e contribuições aos estudos em Psicologia Social. Psicologia: ciência e profissão, v. 30, n. 1, p. 146-161, 2010. 
COSSON, Rildo. Letramento literário: teoria e prática. São Paulo: Contexto, 2006.

DALCASTAGNÈ, Regina. Ver e imaginar o outro: alteridade, desigualdade, violência na literatura brasileira contemporânea. Horizonte, 2019.

DOMINGUES, Diana. Arte e vida no século XXI: tecnologia, ciência e criatividade. Unesp, 2003.

DUARTE, Rosália. Cinema e educação. Belo Horizonte: 4. ed. Autêntica, 2009.

DUARTE JR, João-Francisco. Por que arte-educação? Papirus Editora, 1998.

FERGUSON, Normal et al. (Dir) Dumbo: Disney, 1941. 1 DVD (64 min).

ENDERLE, Carmen. Psicologia do desenvolvimento: o processo evolutivo da criança. Porto Alegre: Artmed, 1985.

GADOTTI, Moacir. Diversidade cultural e educação para todos. Rio de Janeiro: Graal, 1992.

GOMBRICH, Ernst Hans; TORROELLA, Rafael Santos; SETÓ, Javier. Historia del arte. New York: Phaidon, 1997.

GUALDA, Linda Catarina. Literatura e Cinema: elo e confronto. MATRIZes, 3(2), 201-220, 2011.

HOBSBAWM, Eric. A Era das revoluções: Europa 1789-1848. Rio de Janeiro: Paz e Terra, 2007.

KEUNEN, Bart. The plurality of chronotopoes in the modernist city novel: the case of Manhattan Transfer. In: English Studies, 2001, vol. 5, p. 420-436.

MACHADO, Cristiana Lopes; STOLTZ, Tania. Arte, criatividade e desenvolvimento socioemocional de alunos com altas habilidades/superdotação (AH/SD): considerações a partir de Vigotski. Revista Educação Especial, v. 30, n. 58, p. 441-454, 2017.

MCKEE, David. Elmer, o elefante xadrez. Trad. São Paulo: WMF Martins Fontes, 2009.

MELO, Weslei Chaleghi de. A diversidade e a inclusão social na arte: literatura e cinema em diálogo. 2019. 106 f. Dissertação (Mestrado em Ensino de Ciências Humanas, Sociais e da Natureza) - Universidade Tecnológica Federal do Paraná, Londrina, 2020.

MELO, Weslei Chaleghi de; SILVEIRA, Éderson Luís; SANTANA, Wilder Kleber Fernandes de. Literatura e cinema em interação discursiva. Revista Diálogo e Interação, v. 14, n. 1, p. 177-196, 2020.

NÓBREGA, Maria Bernardete da. Murilo Mendes: do pretext plástico à verdade plástica - a intersemiose poesia/pintura em Tempo Esoanhol. Cajazeiras, Arribaçã, 2019.

NORONHA, Lucélia Fernandes Fagundes. A representação da deficiência na literatura infantojuvenil em tempos de inclusão. Tese. São Paulo: Universidade Presbiteriana Mackenzie, 2006.

NUNES, Diogo Cesar. (Im) possível experiência: Literatura e alteridade, teoria crítica e ficção científica. Literatura e Autoritarismo, n. 22, 2013.

O ESPANTA TUBARÕES. Direção: Rob Letterman, Vicky Jenson, Bibo Bergeron: Dreamworks, 2004. 1 DVD (90 min). 
OS SEM FLORESTA. Direção: Tim Johnson, Karey Kirkpatrick: Dreamworks, 2006. 1 DVD (85 min).

RIO. Direção: Carlos Saldanha: Blue Sky, 2011. 1 DVD (96 min).

ROUSSEAU. J. J. Discurso sobre a origem e os fundamentos das desigualdades entre os homens. Coleção Os Pensadores. São Paulo: 2ª edição, Abril Cultural, 1978.

SCHOLZ, Bernhard. Bakhtin's Concept of 'Chronotope': The Kantian Connection. In: SHEPHERD, D. (ed). The Contexts of Bakhtin: Philosophy, Authorship, Aesthetics. Amsterdam: Harwood Academic Publishers, 1998, pp.141-172.

SILVEIRA, Éderson Luís. Santana, Wilder Kleber Fernandes de. "Ele Não" como ato de resistência: notas sobre Bakhtin, Foucault e a necessidade de dizer a verdade em atos responsáveis. In: FRANCELINO, Pedro Farias; SANTANA, Wilder Kleber Fernandes de (Orgs). Bakhtin e o círculo em fronteiras do discurso - vol. 1. São Carlos: Pedro e João Editores, 2019. Pp. 87-116.

TAVARES, Monica. Fundamentos estéticos da arte aberta à recepção. ARS (São Paulo) [online]. 2003, vol.1, n.2, pp.31-43. Disponível em: $<$ http://www.scielo.br/scielo.php?script=sci_arttext\&pid=S1678-53202003000200003>.

Acesso em: 14 mar. 2018.

VENÂNCIO, Ana. Literatura infanto juvenil e diversidade. 2009. 257 p. Dissertação (Mestrado em Educação) - Universidade Federal do Paraná, Curitiba, 2009. Disponível em:

$<$ https://www.acervodigital.ufpr.br/bitstream/handle/1884/19516/Dissertacao\%20PDF.p df?sequence=1>. Acesso em: 06 jul. 2018.

VOLÓCHINOV, Valentin. A Interação Discursiva. In: VOLOCHÍNOV, V. N. (círculo de Bakhtin). Marxismo e filosofia da linguagem - Problemas fundamentais do método sociológico na ciência da linguagem. Tradução de Sheila Grillo e Ekaterina Vólkova Américo - Ensaio introdutório de Sheila Grillo. 1. ed. São Paulo: Editora 34, 2017b [1929]. p. 201-226.

Nota do editor:

Artigo submetido para avaliação em: 06 de março de 2021.

Aprovado em sistema duplo cego em: 06 de agosto de 2021. 